\title{
Genetic background effects of keratin 8 and 18 in a DDC-induced hepatotoxicity and Mallory-Denk body formation mouse model
}

\author{
Johannes Haybaeck ${ }^{1}$, Cornelia Stumptner ${ }^{1}$, Andrea Thueringer ${ }^{1}$, Thomas Kolbe ${ }^{2}$, Thomas M Magin ${ }^{3}$, \\ Michael Hesse ${ }^{4}$, Peter Fickert ${ }^{5}$, Oleksiy Tsybrovskyy ${ }^{1}$, Heimo Müller ${ }^{1}$, Michael Trauner ${ }^{5,6}$, Kurt Zatloukal ${ }^{1}$ \\ and Helmut Denk ${ }^{1}$
}

Keratin 8 (K8) and keratin 18 (K18) form the major hepatocyte cytoskeleton. We investigated the impact of genetic loss of either K8 or K18 on liver homeostasis under toxic stress with the hypothesis that K8 and K18 exert different functions. $\mathrm{krt}^{-1-}$ and $\mathrm{krt} 18^{-/-}$mice crossed into the same 129-ola genetic background were treated by acute and chronic administration of 3,5-diethoxy-carbonyl-1,4-dihydrocollidine (DDC). In acutely DDC-intoxicated mice, macrovesicular steatosis was more pronounced in $\mathrm{krt}^{-/-}$and $\mathrm{krt}^{-18^{-/}}$compared with wild-type (wt) animals. Mallory-Denk bodies (MDBs) appeared in $\mathrm{krt} 18^{-1-}$ mice already at an early stage of intoxication in contrast to $\mathrm{krt}^{-/-}$mice that did not display MDB formation when fed with DDC. Keratin-deficient mice displayed significantly lower numbers of apoptotic hepatocytes than wt animals. $\mathrm{krt}^{-/-}, \mathrm{krt}^{-18^{-1}}$ and control mice displayed comparable cell proliferation rates. Chronically DDC-intoxicated krt $18^{-/-}$and wt mice showed a similarly increased degree of steatohepatitis with hepatocyte ballooning and MDB formation. In $\mathrm{krt8}^{-1-}$ mice, steatosis was less, ballooning, and MDBs were absent. krt18 ${ }^{-1-}$ mice developed MDBs whereas $\mathrm{krt}^{-/-}$mice on the same genetic background did not, highlighting the significance of different structural properties of keratins. They are independent of the genetic background as an intrinsic factor. By contrast, toxicity effects may depend on the genetic background. $\mathrm{krt8}^{-/-}$and $\mathrm{krt} 18^{-/-}$mice on the same genetic background show similar sensitivity to DDC intoxication and almost resemble wt animals regarding survival, degree of porphyria, liver-to-body weight ratio, serum bilirubin and liver enzyme levels. This stands in contrast to previous work where krt8 ${ }^{-/-}$and $\mathrm{krt}^{-18^{-/-}}$mice on different genetic backgrounds were investigated.

Laboratory Investigation (2012) 92, 857-867; doi:10.1038/labinvest.2012.49; published online 26 March 2012

KEYWORDS: DDC; intermediate filaments; keratin deficiency; sclerosing cholangitis; steatohepatitis

Keratins (Ks) form the epithelial intermediate filament (IF) cytoskeleton. ${ }^{1}$ The analysis of $\mathrm{K}$ knockout and transgenic mice revealed that Ks of internal epithelia are major contributors to cell integrity. ${ }^{2-5} \mathrm{Krt} 8$ and $\mathrm{Krt} 18$ are believed to be susceptibility genes for liver disease. In the absence of Ks, overall protein biosynthesis was diminished by $\sim 40 \%{ }^{6}$ Lack or mutation of $\mathrm{K} 8$ or $\mathrm{K} 18$ predispose for liver injury and apoptosis. Survival of K8-deficient $\left(\mathrm{krt}^{-/-}\right)$rodents seems to be determined by facultative modifier genes that differ between $\mathrm{C} 57 \mathrm{Bl} / 6$ and $\mathrm{FVB} / \mathrm{N}$ mice: $\mathrm{krt}^{-1-}$ mice in the $\mathrm{C} 57 \mathrm{Bl} /$ 6 background showed 94\% embryonic lethality associated with placental deficiency whereas $55 \%$ of $\mathrm{FVB} / \mathrm{N} \mathrm{K}^{-1-}$ mice survived. ${ }^{7}$ As previously shown by Hillebrandt et al, ${ }^{8} \mathrm{FVB}$ mice are more resistant to develop liver fibrosis than, eg, BalbC mice. This additional example identified the Hfib1 as an important locus of fibrosis susceptibility. ${ }^{8}$

A relevance of $K$ sequence variants for human liver disease was substantiated by detection of $\mathrm{K}$ mutations in patients of different ethnic backgrounds and with various liver diseases. ${ }^{9-11}$

Expression of a dominant-negative mutant of human K18 in livers of transgenic mice led to chronic hepatitis with hepatocyte fragility and increased susceptibility toward acute

\footnotetext{
${ }^{1}$ Institute of Pathology, Medical University of Graz, Graz, Austria; ${ }^{2}$ Biomodels Austria, University of Veterinary Medicine Vienna, Austria and IFA-Tulln, University of Natural Resources and Applied Life Sciences, Vienna, Austria; ${ }^{3}$ Translational Centre for Regenerative Medicine Leipzig, Institute of Biology, University of Leipzig, Leipzig, Germany; ${ }^{4}$ Division of Cell Biochemistry, Institute of Biochemistry and Molecular Biology, University of Bonn, Bonn, Germany; ${ }^{5}$ Division of Gastroenterology and Hepatology, Department of Internal Medicine, Laboratory of Experimental and Molecular Hepatology, Medical University of Graz, Graz, Austria and ${ }^{6}$ Division of Gastroenterology and Hepatology, Department of Medicine III, Medical University Vienna, Vienna, Austria

Correspondence: Professor J Haybaeck, MD, PhD, Institute of Pathology, Medical University of Graz, Auenbruggerplatz 25, 8036 Graz, Austria.

E-mail: johannes.haybaeck@medunigraz.at

Received 27 September 2011; revised 7 November 2011; accepted 8 November 2011
} 
drug-induced liver injury. ${ }^{12}$ Following administration of hepatotoxins, hyperphosphorylation of K18 on serine residues, an increased level of soluble Ks, and reorganization of the $\mathrm{K}$ cytoskeleton in hepatocytes occurred, suggesting that phosphorylation of Ks has a role in protecting hepatocytes against liver injury and thus serves as 'stress sensor. ${ }^{13-16}$ Ks 8 and 18 are involved in mediating Fas- (but not TNF $\alpha$-) induced apoptosis in hepatocytes and the apoptotic program is enhanced in K-modified cells. ${ }^{17,18}$

Several pathologic conditions including alcoholic steatohepatitis (ASH) and non-alcoholic steatohepatitis (NASH) show a disturbed $\mathrm{K}$ cytoskeleton in ballooned hepatocytes with Ks and p62 as major components of cytoplasmic aggregates termed as Mallory-Denk bodies (MDBs). ${ }^{12,19,20}$ Steatohepatitis-like liver damage with MDB formation can be induced in mice by chronic administration of the porphyrinogenic liver toxins 3,5-diethoxy-carbonyl-1,4dihydrocollidine (DDC) and griseofulvin. ${ }^{19,20}$ Recent studies using different mouse strains revealed that the genetic background significantly determines the liver phenotype in the DDC model which may also be relevant for the variable susceptibility of patients to steatohepatitis. ${ }^{21,22}$ In previous studies, we observed a strikingly higher DDC toxicity with increased lethality of $\mathrm{K}^{-1-}$ mice upon DDC intoxication compared with wild-type (wt) and krt18 ${ }^{-1-}$ animals. ${ }^{23,24} \mathrm{We}$ hypothesized that $\mathrm{K} 8$ protects against oxidative stress, and that the genetic background determines the steatohepatitis phenotype of $\mathrm{krt}^{-1-}$ and $\mathrm{krt1} 8^{-1-}$ mice. We posed the question whether strains rather than $\mathrm{K}$ affect the susceptibility toward MDB formation, steatohepatitis and sclerosing cholangitis. We aimed at dissecting the different properties of $\mathrm{K} 8$ and $\mathrm{K} 18$, and therefore had to backcross both strains to the same genetic background (129-ola) to enable a direct comparison. We therefore generated $\mathrm{krt}^{-/-}$and $\mathrm{krt1} 18^{-/-}$ mice in the same genetic background for direct comparison using the DDC model with special emphasis on resulting steatohepatitis and the behavior of MDBs.

\section{MATERIALS AND METHODS Breeding of Mice}

After having performed embryo transfers heterozygous $\mathrm{krt} 8^{+/-} \mathrm{FVB} / \mathrm{N}$ mice were mated to 129 -ola wt mice over $>10$ generations. ${ }^{2-5}$ Genotypes were determined by PCR analysis of tail DNA. Following primers were used: K8-868 (5'-GGC CCT GCC CTC TAG TGT- $3^{\prime}$ ) and K8-1377 (5'AGG GGT CTC ACC TTG TCA AT- $3^{\prime}$ ) for amplification of the wt allele $\left(\mathrm{K} 8^{+}\right), \mathrm{K} 8-868$ and neo-249 (5'-CCT TCC CGC TTC AGT TAC- $3^{\prime}$ ) for amplification of the mutated allele $\left(\mathrm{K}^{-}\right)$. PCR products were separated on a $1 \%$ agarose gel in $1 \times$ TBE buffer. The expected product from $\mathrm{mK} 8-868$ and $\mathrm{mK} 8-1377$ was $529 \mathrm{bp}$, from $\mathrm{mK} 8-868$ and neo-249 was $700 \mathrm{bp}$. Breeding and genotyping of krt18 ${ }^{-1-}$ 129-ola mice was performed as described previously. ${ }^{2-5}$

\section{Intoxication}

Homozygous male $\mathrm{krt}^{-1-}$, krt18 ${ }^{-1-}$ and Wt 129-ola mice ( 2 months old, body weight $25-30 \mathrm{~g}$ ) were kept under SPF conditions and fed a standard diet (ssniff Spezialitäten $\mathrm{GmbH}$, Soest, Germany) and water ad libitum. For experimental induction of steatohepatitis, mice received standard diet containing 0.1\% DDC (Aldrich, Steinheim, Germany) for 1 and 12 weeks, respectively. At each time point and in each experimental group, 5-10 mice were killed by cervical dislocation, body and liver weights were determined, serum samples were analyzed, and the livers were further processed as indicated below. All experiments were approved and conform to the guidelines of the Austrian Animal Protection Law, Veterinary office, Vienna, Austria. The experimental protocol was approved by the Federal Animal Care and Use Committee.

\section{Light Microscopy}

Murine liver tissues were either snap frozen in methylbutane precooled in liquid nitrogen or fixed in $4 \%$ formaldehyde solution in PBS, embedded in paraffin, and $7 \mu \mathrm{m}$ thick sections were cut and subsequently stained with hematoxylin and eosin (HE) or Sirius red, respectively. Apoptotic hepatocytes were determined by their morphological features of showing eosinophilic cytoplasms and shrunken nuclei.

\section{Immunofluorescence Microscopy}

Murine liver tissues were snap frozen in methylbutane precooled in liquid nitrogen for immunofluorescence microscopy, which was performed as described previously. ${ }^{23,25,26}$ Apoptosis was detected by immunofluorescence microscopy on cryosections fixed with acetone using a polyclonal antibody against activated caspase 3 and a rhodamin-conjugated secondary antibody. For quantitative determination, positive hepatocytes were counted in $20-40$ microscopic fields $(\times 250$ magnification).

\section{Immunohistochemistry}

Murine liver tissues were fixed in $4 \%$ formaldehyde solution in PBS, embedded in paraffin, and $7 \mu \mathrm{m}$ thick sections were cut and subsequently used for immunohistochemistry, was performed as described. ${ }^{19,20,23,25,26}$ For determination of the proliferation status, $\mathrm{Ki}-67^{+}$and $\mathrm{PCNA}^{+}$hepatocyte nuclei were counted in 10 high power fields (HPF; $\times 400$ magnification) and mean values ( \pm s.d.) were calculated.

\section{Immunoelectron Microscopy}

Immunoelectron microscopy was performed for MDB characterization as described previously. ${ }^{23,25,26}$

\section{Bile Duct/Ductule Morphometry}

Morphometry of osteopontin (OPN) expression in bile ducts and ductules was performed using a semiautomatic system for image analysis. This consisted of a microscope (Nikon E600; Tokyo, Japan), a video camera (Sony DXC-930P; 
Tokyo, Japan), a frame grabber (Intrigue Pro; Integral Technologies, Indianapolis, IN), and a computer with image analysis software (Optimas 6.51; Media Cybernetics, Bethesda, MD). A macro-command served for automatic identification and measurement of the total area of $\mathrm{OPN}^{+}$ cells within a given portal field. All portal fields (13-31) in each sample were measured.

\section{Porphyrin Determination}

Total porphyrin content was determined as described previously. ${ }^{23}$ Brown pigment in liver tissue of intoxicated mice indicating porphyrin deposition was quantified morphometrically by evaluating $38-134$ randomly selected HPF.

\section{Immunoblotting}

$\mathrm{K} 8$ and $\mathrm{K} 18$ proteins were analyzed in liver homogenates of control, 1 and 12 weeks DDC-fed wt and $\mathrm{krt}^{-1-}$ mice by immunoblotting using rabbit antibody 50K160 directed to both Ks. ${ }^{27}$

\section{Quantitative Real-Time PCR}

Routine protocols were performed. Primers and probes (synthesized by MWG-Biotech AG, Germany) are listed in Table 1.

\section{Statistical Analysis}

Data are reported as median values with $95 \%$ confidence interval limits. These estimates were computed by nonparametric bootstrap using DATAPLOT software (National Institute of Standards and Technology, Statistical Engineering Division, Gaithersburg, MD, USA). Morphometric data present a hierarchical structure, where portal fields or fields of view (level-one sampling units) are nested within mice (level-two sampling units). A two-level linear regression model by means of MLwiN 2.02 software (Centre for Multilevel Modelling, University of Bristol, UK) was fitted to calculate mean values and confidence intervals. Finally, a two-way ANOVA with Bonferroni post-test was performed to test the significance of differences between groups.
RESULTS

Effect of DDC Intoxication on Liver Weight, Serum Bilirubin and Hepatic Porphyrin Levels are Independent of the Keratin Status, While Transaminase Levels and Ductular Reaction Are Aggravated in krt18 ${ }^{-1-}$ Mice

The livers of DDC-fed (treatment for 1 and 12 weeks, respectively) compared with normal diet-fed $\mathrm{wt}, \mathrm{krt}^{-1-}$ and krt $18^{-1-}$ mice were markedly enlarged. Liver-to-body weight ratios did not differ between wt and K-deficient mice on normal control diet $(P>0.05$; Figure 1a). DDC intoxication led to similar significant increase of liver-to-body weight ratios in all groups ( ${ }^{* * *}, P<0.0001$; Figure 1a). Serum bilirubin levels rose with duration of DDC intoxication equally in wt and K-deficient mice (**, $P=0.004$; Figure $1 \mathrm{~b})$. In control diet-fed mice, $\mathrm{K}$ deletion had no influence on distribution and quantity of bile ducts and ductules. DDC treatment for 1 week led to ductular reaction without significant difference between the experimental groups. Bile duct areas increased in chronically DDC-intoxicated mice (***, $P<0.0001)$. However, ductular reaction was significantly more pronounced in $\mathrm{krt}^{-1}$ - and $\mathrm{krt}^{-18^{-1}}$ mice when compared with DDC-intoxicated wt mice ${ }^{*}, P=0.02$ or $P<0.05$, respectively; Figure 1 c).

Alkaline phosphatase (ALP) levels rose equally in acutely and chronically intoxicated animals (Figure 1d). Serum aminotransferase (AST, ALT) levels peaked after short-term intoxication and dropped in the chronic stage (Figures 1e and f). In 1-week DDC-treated mice, AST levels were significantly higher in $\mathrm{krt}^{-1} 8^{-1}$ mice compared with wt (***, $P<0.0001$ ), while in $\mathrm{krt}^{-1-}$ they did not significantly differ from wt mice (Figure 1e).

Activated caspase $3^{+}$hepatocytes were sparse in all groups, which were fed with normal diet. Upon DDC treatment for 1 week significantly increased numbers of hepatocytes with caspase 3 activation were found in wt as well as in K-deficient mice with significant difference between wt and $\mathrm{krt}^{-1-}$ or krt18 $8^{-1-}$ mice $\left({ }^{*}, P=0.02\right.$; Figure $\left.2 \mathrm{a}\right)$. Upon challenge with DDC for 12 weeks, the K-deficient groups showed a significantly lower number of hepatocytes with caspase 3 activation in

Table 1 Primer sequences for quantitative real time PCRs.

\begin{tabular}{|c|c|c|c|c|}
\hline Gene & Acc. no. & Primer/probe (dye label) & Sequence $5^{\prime}-3^{\prime}$ & Product length \\
\hline p62 & NM_011018 & Forward primer & ACCCACAGGGCTGAAGGAAGCT & $124 \mathrm{bp}$ \\
\hline \multirow[t]{2}{*}{ Hmox 1} & NM_010442 & Forward primer & CACTTCGTCAGAGGCCTGCTA & $93 \mathrm{bp}$ \\
\hline & & Reverse primer & GTCTGGGATGAGCTAGTGCTGAT & (Pos 925-832) \\
\hline & & Reverse primer & CTGGGCACTGCGGAGAAAATGAC & (Pos 115-41) \\
\hline \multirow[t]{2}{*}{ mK8 } & NM_031170 & Forward primer & TGAACAACAAGTTCGCCTCCTT & $109 \mathrm{bp}$ \\
\hline & & Reverse primer & GCTCCTCGACGTCTTCTGCT & (Pos 523-414) \\
\hline \multirow[t]{2}{*}{$\mathrm{mK} 18$} & NM_010664 & Forward primer & GGCTCAGATCCTTGCGAATTC & $84 \mathrm{bp}$ \\
\hline & & Reverse primer & TCTAAAGTCATCGGCGGCA & (Pos 5128-444) \\
\hline
\end{tabular}


a

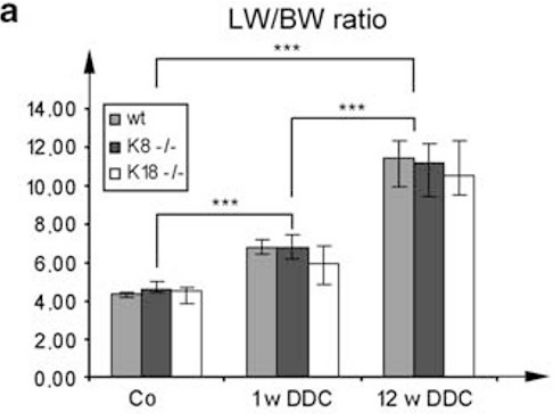

C

Relative bile duct area

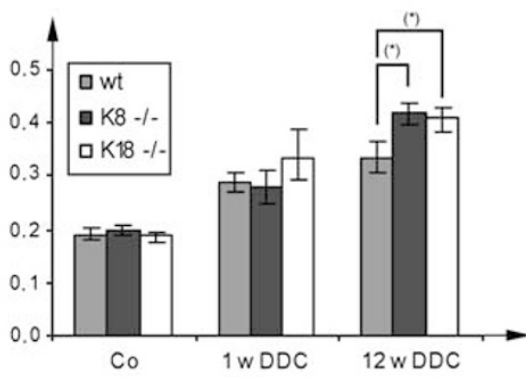

e

AST

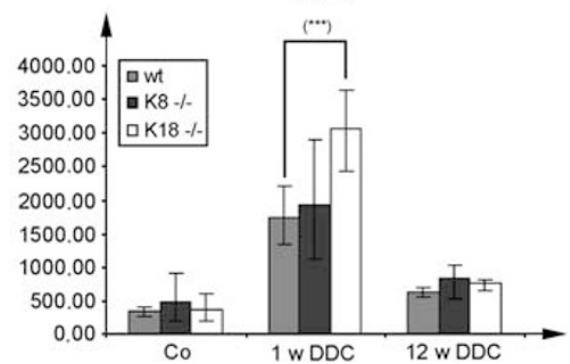

b

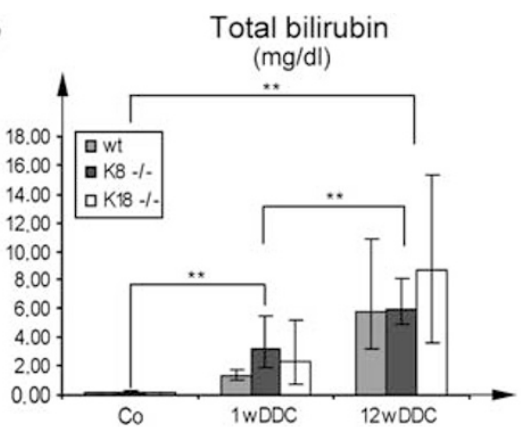

d

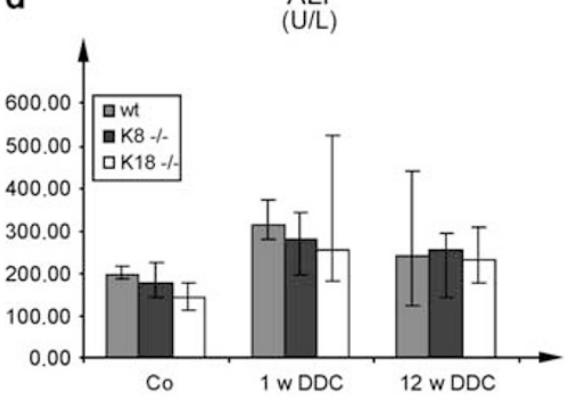

f

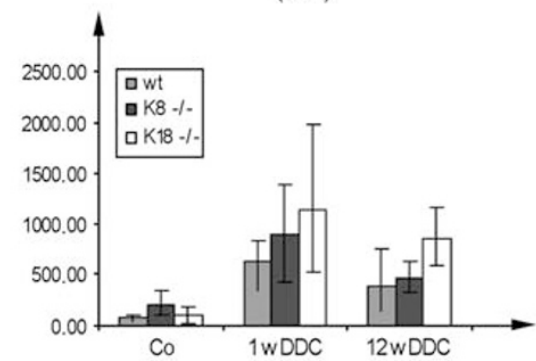

Figure 1 Liver-to-body weight ratios (LW/BW ratio), total bilirubin, serum enzyme levels (alkaline phosphatase, ALP; aspartate aminotransferase, AST; alanine aminotransferase, ALT) and relative bile duct areas in control (Co), 1 week (1w DDC) and 12 weeks (12w DDC) intoxicated wild-type (wt), K8 (krt8 ${ }^{-1-}$ )and K18 (krt18 ${ }^{-1-}$ )-deficient mice. (a) LW/BW ratio: significant increase $(P<0.05)$ in all experimental groups. (b) Total bilirubin: significant increase $(P<0.05)$ in all experimental groups. (c) Relative bile duct area: significant difference between $12 \mathrm{w}$ DDC K-deficient and 12w DDC wt mice $(P<0.05)$. (d) ALP: no significant differences. (e) AST: significant difference between $1 \mathrm{w}$ DDC krt18 ${ }^{-1-}$ and $1 \mathrm{w}$ DDC wt mice $(P<0.05)$ and between all $1 \mathrm{w}$ DDC and all $12 \mathrm{w}$ DDC mice $(P<0.05)$. (f) ALT: no significant differences.
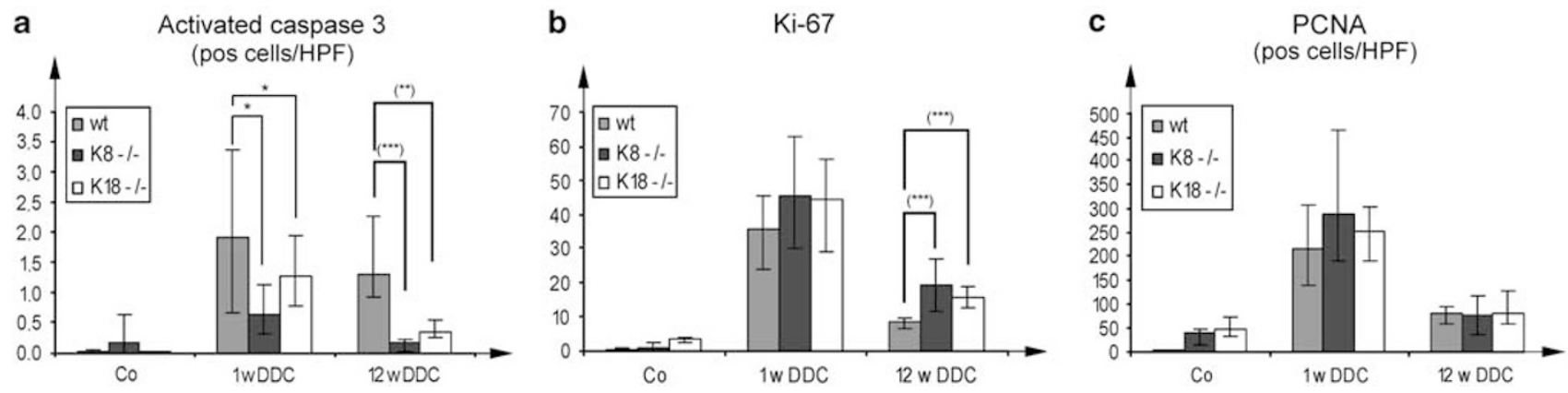

Figure 2 (a) Activated caspase 3: significant difference between 12w DDC K-deficient and 12w DDC wt mice $(P<0.05)$. (b) Ki-67: significant difference between all DDC-treated and control mice and between 12w DDC K-deficient and wt mice $(P<0.05)$. (c) PCNA: significant difference between all 1w DDC and control mice and between all 1w DDC and all 12w DDC mice $(P<0.05)$. 
comparison with wt animals. The decrease was more pronounced in $\mathrm{krt}^{-l-}(* * *, P<0.0001)$ than in $\mathrm{krt1}{ }^{-/-}$animals $(* \star, P=0.002$; Figure 2a).

In contrast to wt animals, in 1-week DDC-fed $\mathrm{krt}^{-1-}$ and krt18 ${ }^{-/-}$mice a slight but not significant increase of Ki- $67^{+}$ and $\mathrm{PCNA}^{+}$nuclei was noted (Figures $2 \mathrm{~b}$ and $\mathrm{c}$ ). Upon longterm intoxication, cell proliferation was significantly lower compared with short-term intoxication but still higher than in the animals fed control diet. $\mathrm{krt}^{-1-}$ and $\mathrm{krt} 18^{-l-}$ mice significantly exceeded wt mice in this regard (***, $P<0.0001$; Figures $2 \mathrm{~b}$ and $\mathrm{c}$ ). These findings suggest that lack of $\mathrm{K}$ causes more hepatocellular injury with a higher cellular turnover, independent of a higher susceptibility toward apoptosis. Confluent necrosis, morphologically resembling bile infarcts, was occasionally seen in acinar zone 1 (data not shown). Necrotic hepatocytes surrounded and penetrated by neutrophils were disseminated throughout the hepatic lobules in $\mathrm{K}^{-/-}$ and $\mathrm{K} 8^{-/-}$mice. Interestingly, the sensitivity of transaminase levels for measuring cell death seems to be low while it is high for detection of cell turnover in this model.

DDC feeding resulted in protoporphyria in all experimental groups and liver porphyrin content significantly increased with duration of treatment ${ }^{* *}, P<0.002$; Figures $3 \mathrm{a}$ and $\mathrm{b}$ ). Liver porphyrin content was slightly higher, although variable, in the $\mathrm{krt}^{-/-}$group. These findings agreed with morphometrically assessed hepatic pigment deposition (Figures $3 \mathrm{a}-\mathrm{c}$ ). After 12 weeks of DDC feeding, the accumulation of pigment was significantly higher than after 1 week of DDC treatment $\left({ }^{*}, P=0.03\right.$; Figure $\left.3 c\right)$. Therefore, DDC-induced porphyria is independent of the $\mathrm{K}$ status.

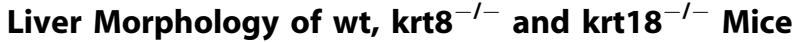 Differs upon Feeding with Normal Diet and DDC for 1 or 12 Weeks}

Wt mice on control diet displayed normal liver morphology. A very mild predominantly macrovesicular steatosis without zonal predominance was observed in wt mice upon 1-week DDC feeding.

In addition to porphyria with pigment-containing macrophages and ductular reaction induced by DDC feeding, morphological features similar to human steatohepatitis were present. The latter were scored according to Brunt (NAS score) ${ }^{28} \mathrm{Wt}$ and $\mathrm{krt}^{-1-}$ hepatocytes showed microvesicular and macrovesicular steatosis, and steatosis was more pronounced in $\mathrm{krt}^{-/-}$than in wt mice.

No significant difference in the activity (and fibrosis) scores was observed between $\mathrm{krt1}^{-/-}$and wt mice $(P>0.05)$. Activity scores in $\mathrm{krt}^{-1-}$ mouse livers were significantly lower than in wt mice $\left({ }^{*}, P=0.002\right)$, particularly due to less pronounced ballooning (Figure $3 \mathrm{~d}$ ).

Confluent necroses, morphologically resembling bile infarcts, were occasionally seen in acinar zone 1 in all animals investigated (data not shown). Upon DDC treatment for 12 weeks, wt and K-deficient mice displayed sclerosing cholangitis with pigment-containing interlobular bile ducts, ductules and pronounced ductular reaction. Inflamed bile ducts were surrounded by fibroblasts. The liver parenchyma showed conspicuous anisocytosis, apoptotic bodies, ballooning and MDB formation in wt mice.

$\mathrm{krt}^{-1-}$ and $\mathrm{krt} 18^{-1-}$ mouse livers revealed disseminated but predominantly subcapsular hemorrhagic parenchymal necrosis, disseminated erythrocyte-containing hepatocytes and parenchymal areas with syncytial changes of the latter as described previously (Figure 3e). ${ }^{29}$ Necrotic hepatocytes surrounded and penetrated by neutrophils were disseminated throughout the hepatic lobules in $\mathrm{krt}^{-/-}$and $\mathrm{krt} 18^{-/-}$mice.

\section{K8 but not K18 Is Essential for MDB Formation}

Upon DDC feeding in wt mice, keratin antibodies were used to stain the IF cytoskeleton network in hepatocytes. Hepatocytes of K-deficient mice lacked K-IF staining (Figure 4a). In DDCfed wt mice, $p 62$ antibodies revealed small granules present in few disseminated hepatocytes or small clusters of hepatocytes with enlarged nuclei predominantly in periportal areas. Only few of these cells contained larger cytoplasmic $\mathrm{p} 62^{+}$clumps. This was also observed in livers of $\mathrm{krt}^{-/-}$and $\mathrm{krt}^{-18^{-/-}}$mice (Figures $4 \mathrm{a}$ and b). In $\mathrm{krt}^{-1-}$ mice, MDBs were absent while in $\mathrm{krt1} 18^{-1-}$ mice numerous $\mathrm{p} 62^{+}$MDBs (indicated by their K8, p62 and ubiquitin content) were found (Figures $4 \mathrm{a}$ and b).

In $\mathrm{krt}^{-1-}$ mice, medium-sized granules, positive for $\mathrm{p} 62$, in few disseminated hepatocytes were also stainable for ubiquitin (data not shown). In wt mice, $\mathrm{K}$ antibodies revealed increased K-IF density in enlarged hepatocytes. In krt18 ${ }^{-1-}$ mice, numerous $\mathrm{K}^{+}$cytoplasmic granules (also $\mathrm{p}^{+} 2^{+}$and ubiquitin $^{+}$), resembling early stages of MDBs, but also typical larger MDBs were present in hepatocytes lacking K-IF (Figures $4 \mathrm{a}$ and $\mathrm{b}$ ). In $\mathrm{krt}^{-1-}$ mice, no $\mathrm{K}^{+}$hepatocytes but $\mathrm{K}^{+}$bile duct epithelial cells were detectable. These data suggest that K8 and K18 fulfill different roles in MDB formation, as K8 but not K18 are essential for MDB formation.

\section{Ultrastructure of MDBs in wt and $\mathbf{k r t 1 8}^{-/-}$Mice}

Ultrastructurally MDBs of $\mathrm{krt}_{1} 8^{-1-}$ mice consisted of an irregular meshwork of short filamentous rods. Compared with MDBs in wt mice, the filaments were identical in size but less tightly packed (Figure 4c).

\section{OPN in Livers of wt, $\mathbf{k r t 8}^{-/-}$and $\mathbf{k r t 1 8}^{-I-}$ Mice Treated for 1 or 12 Weeks with DDC}

Since OPN is upregulated in patients with steatohepatitis and sclerosing cholangitis and correlates with fibrosis, we also explored a potential relationship between OPN and Ks in our model. ${ }^{30-33}$ OPN immunostaining was positive in acinar zone 1 hepatocytes in 1-week DDC-fed wt and K-deficient mice (Supplementary Figure 1). This expression pattern got lost upon chronic intoxication corroborating previous findings of decreased hepatic opn mRNA expression under this condition. ${ }^{34}$ In contrast, all DDC-challenged groups displayed strong granular cytoplasmic staining in bile duct and ductular epithelia (Supplementary Figure 1). Investigation of 
a

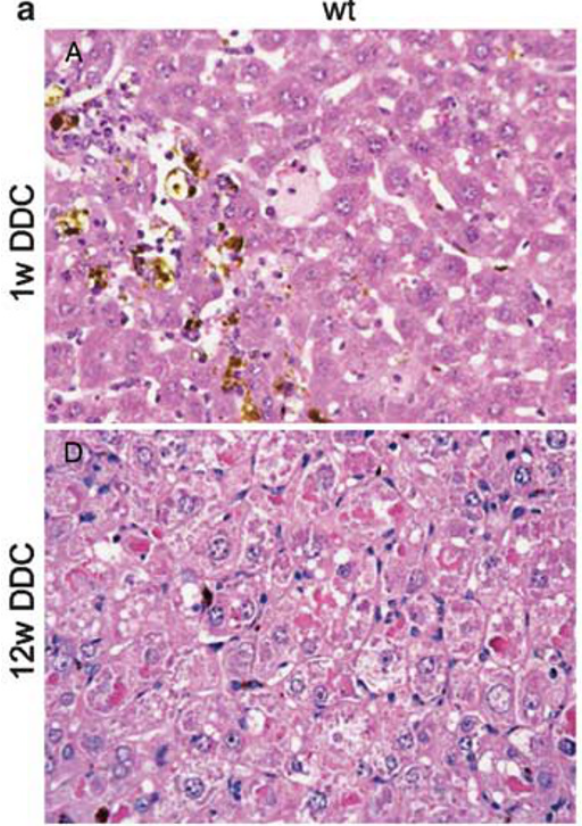

krt $8^{-1-}$
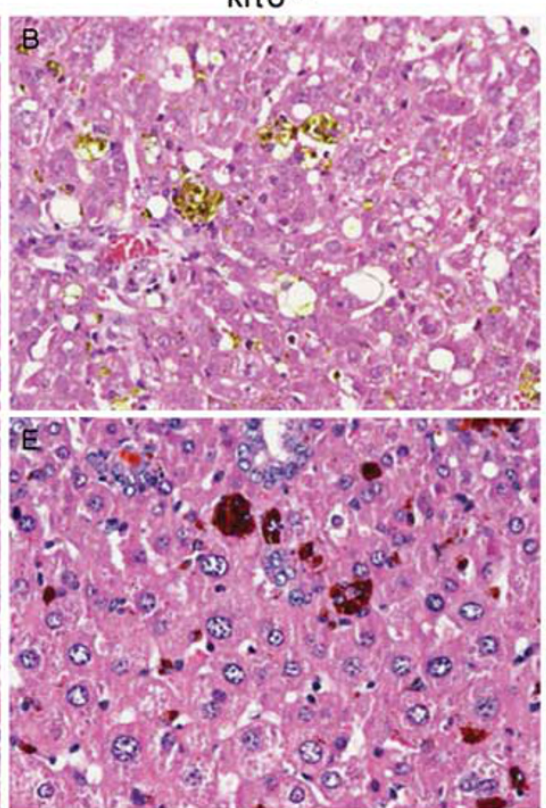

krt18-
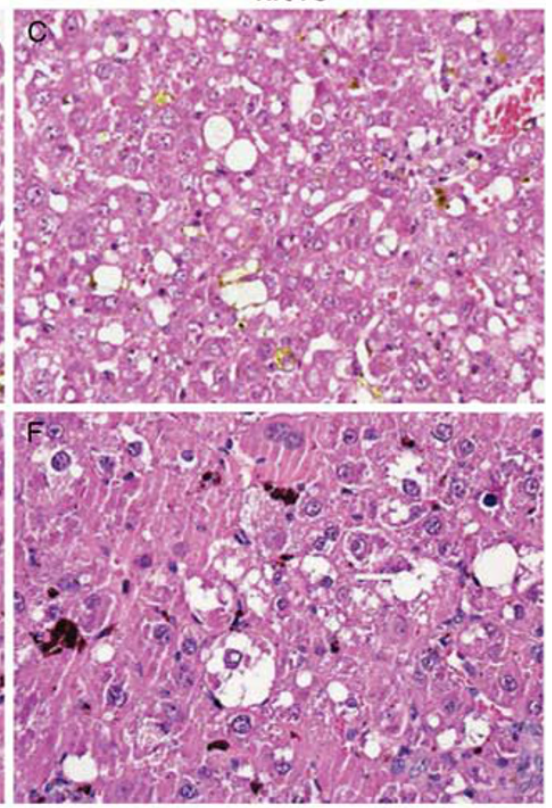

b

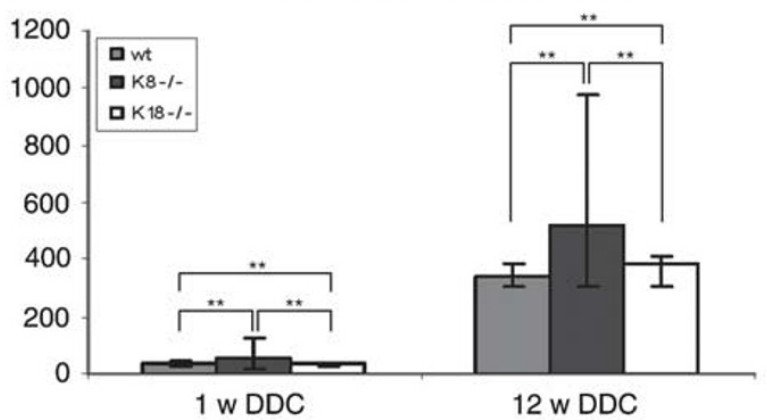

c

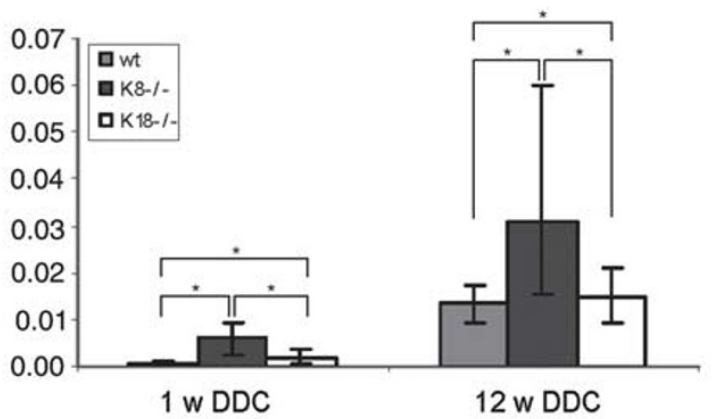

d

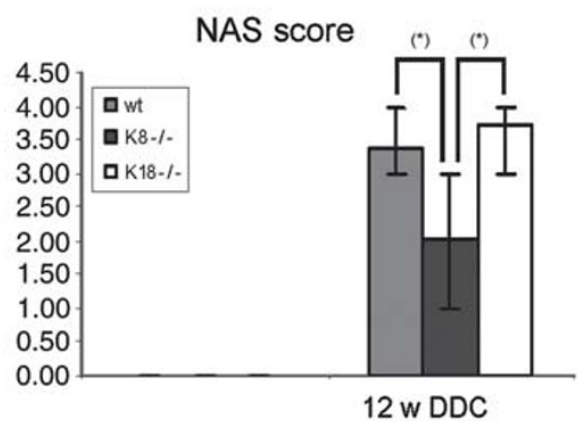

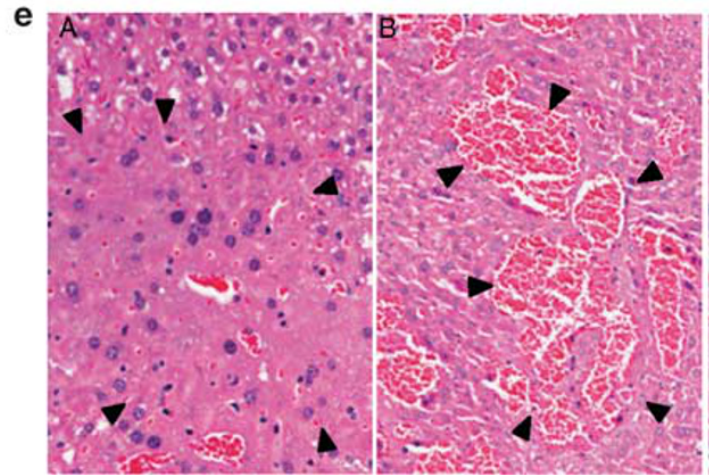

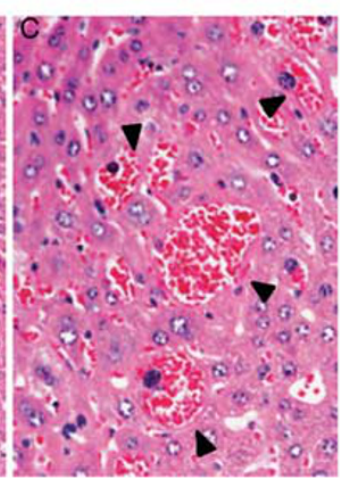

Figure 3 Steatohepatitis and protoporphyria in DDC-intoxicated wt and K-deficient mice. (a) After 1 week of DDC treatment (1w DDC), steatosis is more pronounced in $\mathrm{krt}^{-1-}$ and $\mathrm{krt}^{-1} 8^{-1}$ than in wt livers (compare A with B and C). Chronic DDC intoxication (12w DDC) is associated with hepatocyte ballooning, steatosis (and MDB formation, not clearly visible in this figure) in wt and krt $18^{-1-}$ livers (D and F). krt8 ${ }^{-1-}$ liver (E) shows less steatosis and lack ballooning and MDB formation (compare E with D and F). Protoporphyrin IX concentration (b) and pigment accumulation (c) are most conspicuous in livers of chronically (12w DDC) intoxicated mice. Liver protoporphyrin concentration is higher and pigment deposition more pronounced in krt8 ${ }^{-1-}$ than in wt and $\mathrm{K}_{1} 8^{-1-}$ mouse livers. However, due to considerable variation between animals the difference is not statistically significant. (d) NASH activity score (NAS

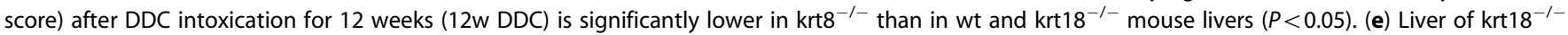
mouse on control diet with parenchymal syncytial areas ( $A$, delineated by arrowheads), extensive hemorrhagic necrosis ( $B$, delineated by arrowheads) and hepatocytes containing erythrocytes (C, arrowheads); H-E staining. 
a
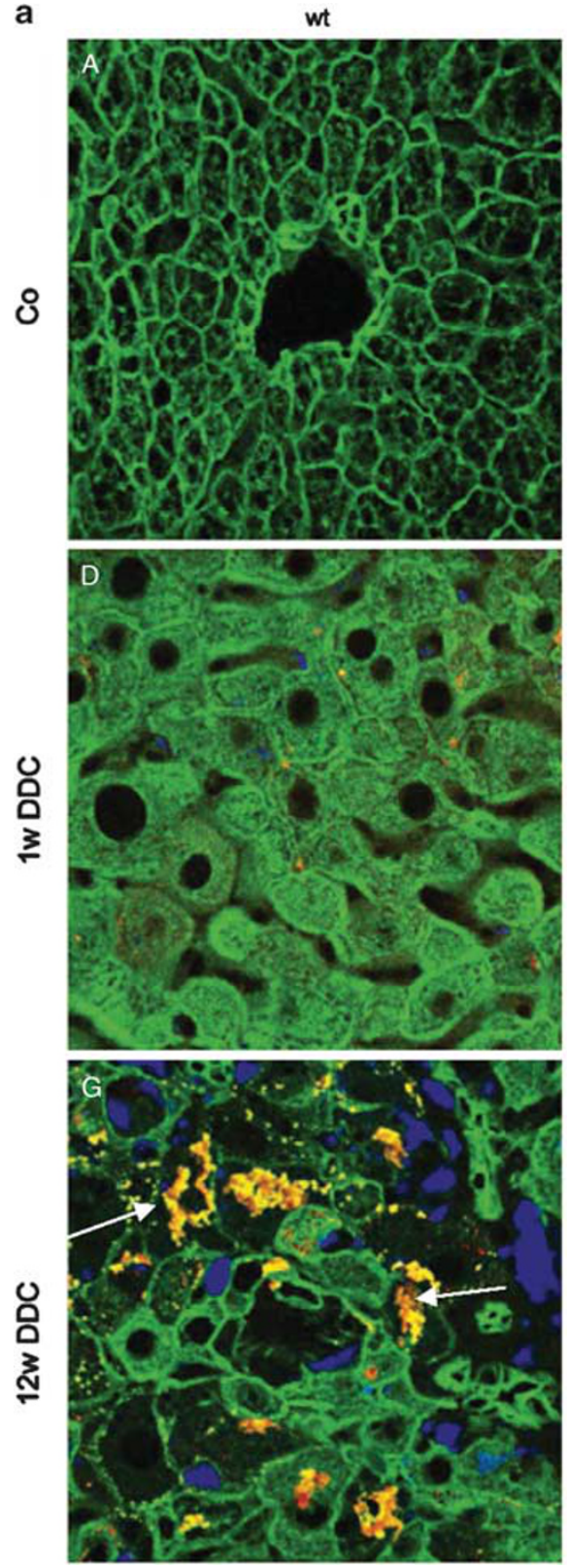

$K 8^{-1}$
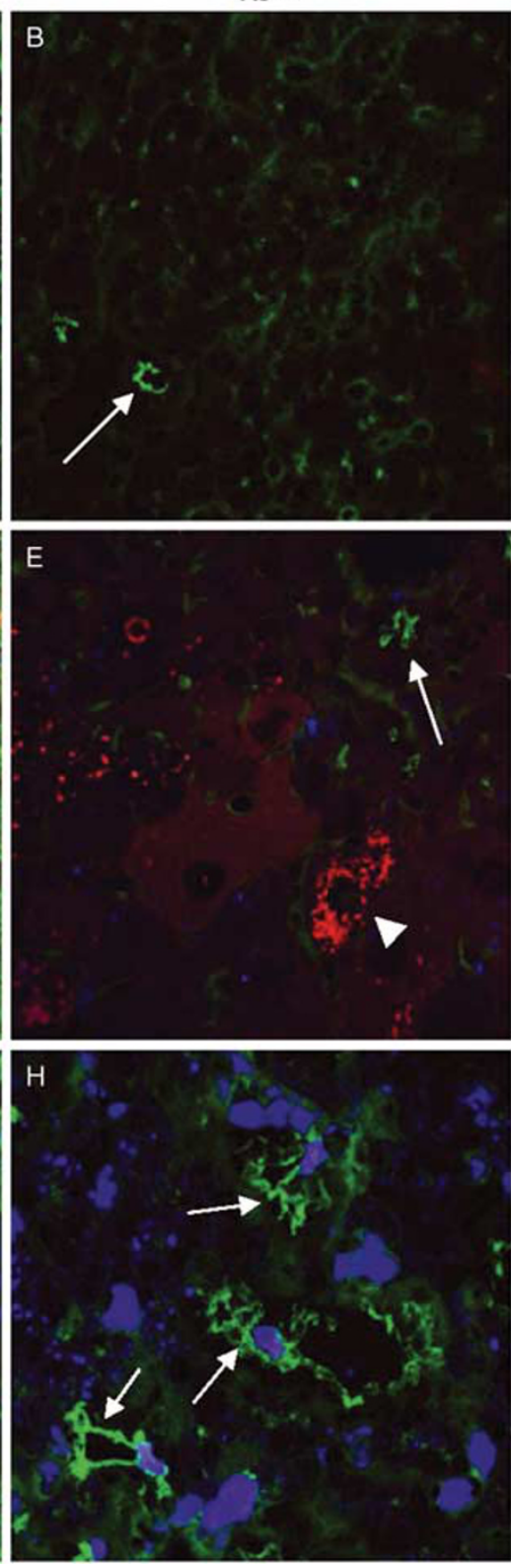

$\mathrm{K} 18^{-1-}$
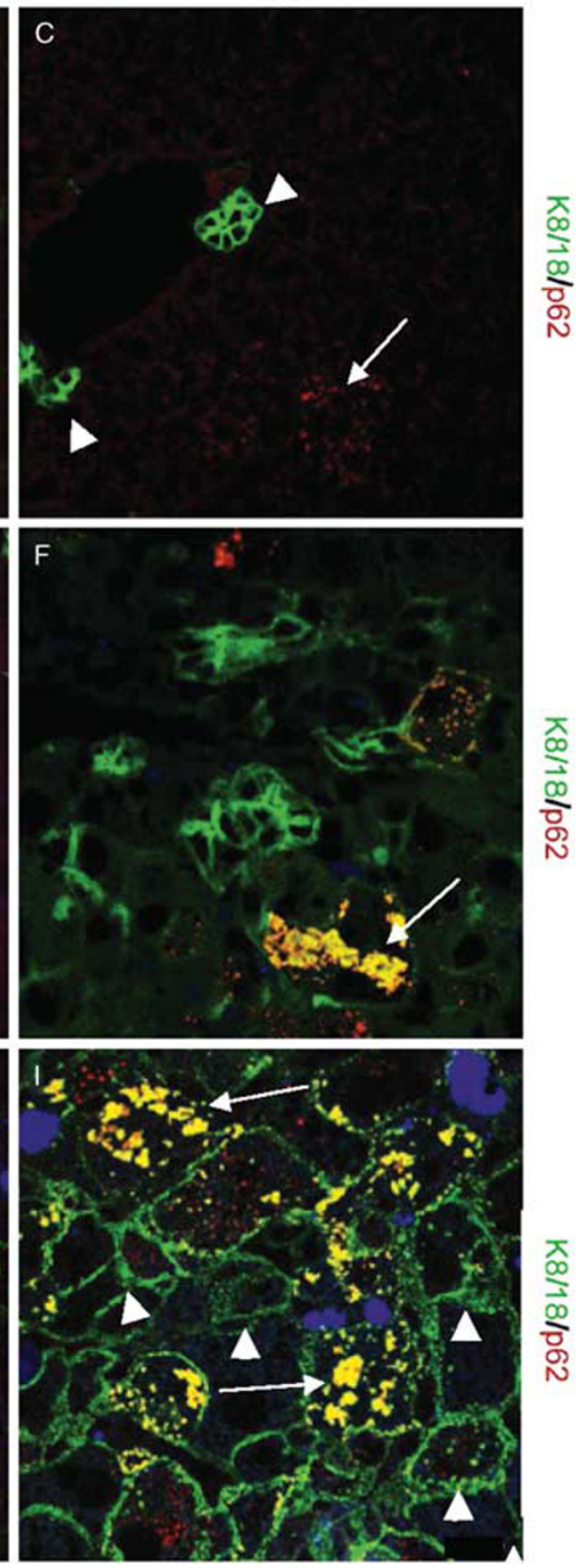

Figure 4 Double immunofluorescence microscopy, immunoelectron microscopy (IEM) of Ks in wt and K-deficient mouse livers. (a) K and p62 in DDC-intoxicated wt and K-deficient mice detected by double immunofluorescence microscopy against Ks 8 and 18 (K8/18; green) and p62 (red). Colocalization of the antigens is indicated by yellow color. The wt control mouse liver (Co) shows regular K-IF cytoskeleton network without p62 accumulation (A). DDC intoxication for 1 week (1w DDC) leads to enlargement of hepatocytes and increased density of the IF cytoskeleton (D). Chronic DDC intoxication (12w DDC) produces profound parenchymal damage with hepatocyte ballooning, diminution or even disappearance of the IF cytoskeleton and granular and larger MDBs (arrows in G). In $\mathrm{K}^{-/-}$mice on normal diet (Co), hepatocytes are unstained by K (K) 8/18 and p62 antibodies. Only lumen-oriented linear cytoplasmic $K$ staining of cholangiocytes is present ( $B$; arrow). In short-term (1w DDC) DDC-intoxicated mice in addition to a superficial linear K18 staining of cholangiocytes (arrow), granular p62 is deposited in disseminated hepatocytes (E; arrowhead). In 12w DDC-intoxicated mouse livers, MDBs are absent and only the K18-related immunostaining of cholangiocytes remains $\left(\mathrm{H}\right.$; arrows). In krt $18^{-1-}$ mice, only cholangiocytes retain $\mathrm{K}$ cytoplasmic staining (arrowheads in C). Occasional hepatocytes contain p62 granules (C; arrow). In 1w DDC-intoxicated mice, MDBs are already present (F; arrow). Some hepatocytes also contain p62 in granular form. Cholangiocytes display cytoplasmic K8 immunostaining (arrowheads). Long-term DDC-intoxicated krt18 ${ }^{-/-}$ livers (12w DDC) resemble wt mice with respect to MDB formation (arrows). K8 immunostaining is retained at the periphery of some hepatocytes (arrow heads in I). p62 granules not associated with Ks are also seen (red in I). Porphyrin pigment is depicted in blue (eg, H and I). (b) K8, p62 and ubiquitin immunohistochemistry in DDC-fed krt18 $8^{-1-}$ mice. (c) IEM of MDBs induced by $12 \mathrm{w}$ DDC feeding in wt type (A and C) and krt18 ${ }^{-1-}$ (B and D) mice. The K8 immunoreaction is indicated by $18 \mathrm{~nm}$ gold particles, presence of p62 by $10 \mathrm{~nm}$ gold particles. In the wt setting, MDBs are closely associated with bundles of IF (indicated in A by arrowheads) in the krt18 ${ }^{-/}$situation IF are lacking. Labeling with gold particles of different sizes indicating the presence of K8 and p62 is highlighted at higher magnification in (C) and (D). Bars represent $1.5 \mu \mathrm{m}$ (B) and $240 \mathrm{~nm}$ (D), respectively. 
b

K8

p62

Ubi
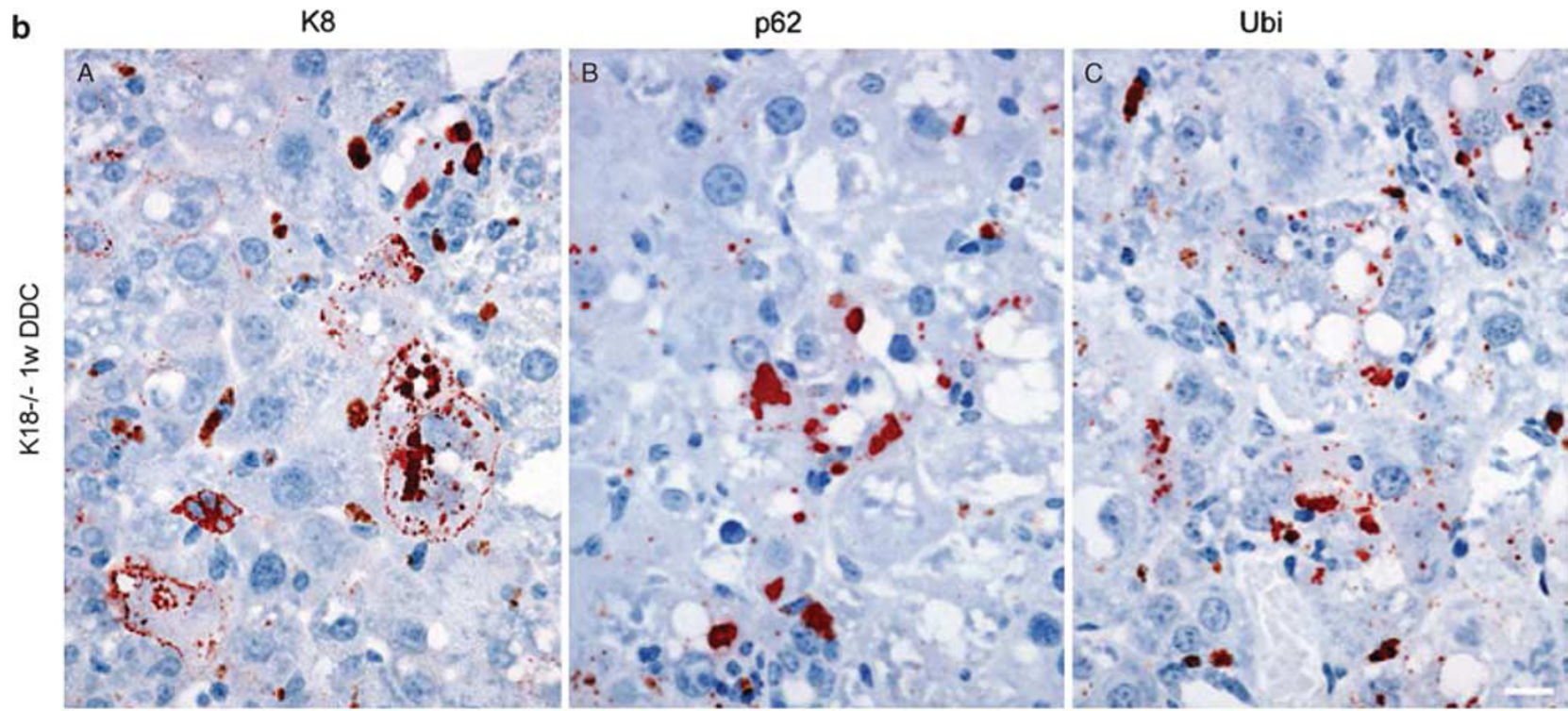

C

wt

$\mathrm{K} 18^{-\%}$

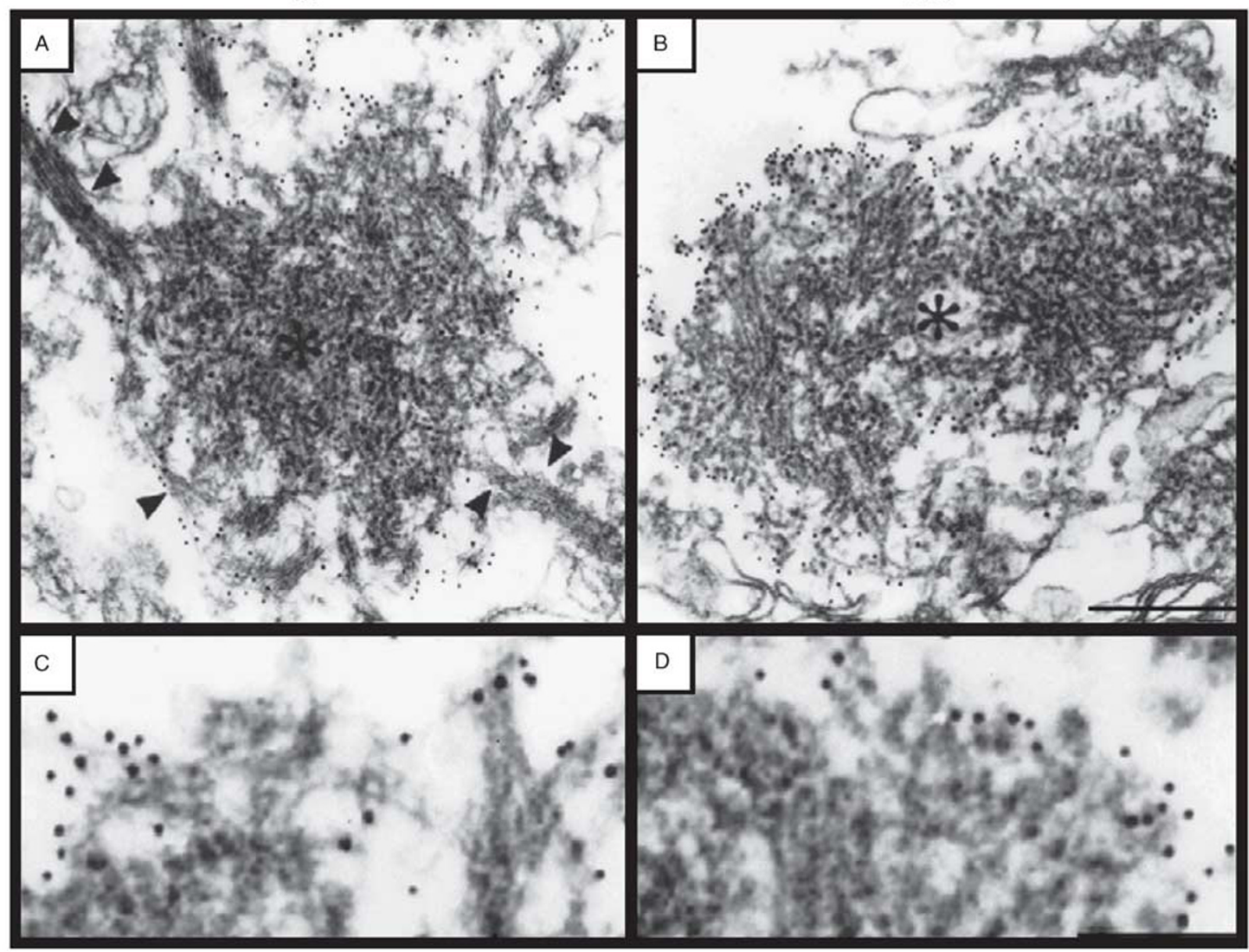

IEM: p62 (10 nm) / K8 (18 nm)

Figure 4 Continued. 
OPN could therefore reconfirm a steatohepatitis and sclerosing cholangitis phenotype driven by DDC.

\section{Effects of DDC Intoxication on Keratin Protein and mRNA Expression}

Upon DDC intoxication for 1 week, Ks 8 and 18 were overexpressed on mRNA and protein level in wt mice (Supplementary Figures $2 \mathrm{a}-\mathrm{c}$ ). Chronic DDC intoxication was also associated with an increase of Ks 8 and 18 mRNA in wt livers, although less pronounced than in the acutely intoxicated animals, while $K 8$ mRNA remained undetectable in $\mathrm{krt}^{-l-}$, and so was $K 18 \mathrm{mRNA}$ in $\mathrm{krt} 18^{-/-}$livers. In krt18 $8^{-1-}$ liver, $K 8$ mRNA increased to a similar extent, whereas in the $\mathrm{krt}^{-1-}$ setting, the increase in $K 18 \mathrm{mRNA}$ was significantly less (Supplementary Figure 2c). Western blot analysis of liver homogenates from chronically intoxicated $\mathrm{krt}_{18}{ }^{-I-}$ mice revealed a K8-specific signal despite the absence of its type I partner under this condition (Supplementary Figure 2a), as corroborated by immunofluorescence microscopy (Supplementary Figure 2b).

\section{DISCUSSION}

In earlier studies, we found increased sensitivity of $\mathrm{krt}^{-/-}$ $\mathrm{FVB} / \mathrm{N}$ mice to DDC intoxication as indicated by higher lethality and development of more severe protoporphyria. ${ }^{23}$ These studies were later extended by including krt18 ${ }^{-/-}$ animals although with different (ie, 129-ola) genetic background. ${ }^{26}$ Surprisingly, in these mice, krt18 deficiency did not cause increased sensitivity to DDC intoxication. This indicates that strain differences have a facultative modifying effect on the role of $\mathrm{K}$ in response to intoxication. ${ }^{23}$

However, the present study uncovered differences between control and K-deficient mice of the same genetic background (129-ola) and between $\mathrm{krt}^{-/-}$and $\mathrm{krt}^{-18^{-1-}}$ mice with respect to hepatotoxicity and MDB formation.

The early appearance of DDC-induced MDBs in krt18 $8^{-1-}$ mice supports previous findings indicating the importance of excess of K8 resulting in imbalance of the K8-to-K18 ratio for MDB formation. The key role of K8 for MDB formation is also supported by spontaneous development of MDBs in old $\mathrm{K} 18^{-1-}$ mice and in mice engineered to overexpress $\mathrm{K} 8$, the absence of MDBs in DDC-intoxicated $\mathrm{krt}^{-1-}$ mice and inhibition of MDB formation by overexpression of K18. ${ }^{35-37}$ However, excess $\mathrm{K} 8$ alone is not sufficient to cause MDB formation, as revealed by acutely DDC-intoxicated wt mice that have sufficient K8. Recent work by our group uncovered molecular and cellular properties of MDB components by using polyelectrolyte probes as new diagnostic tool. In this study, we found out that cross $\beta$-sheet conformation of MDBs depends on oxidative stress and K8 but not on p62. ${ }^{38}$ Luminescent-conjugated oligothiophenes (LCOs), h-HTAA and p-FTAA are fluorescent amyloid ligands specifically binding proteins with cross $\beta$-sheet conformation. We used LCOs to investigate conformational changes in MDBs in situ in human and murine livers as well as in transfection studies.
In conclusion, the readiness of $\mathrm{K} 8$ to undergo conformational changes from predominantly $\alpha$-helical to cross $\beta$-sheet explains its essential role in MDB formation. This could also be a molecular structural explanation why the absence of K8 prevents MDB formation while its excess facilitates MDB formation.

The different behavior of $\mathrm{K} 8$ and $\mathrm{K} 18$ could be explained by the fact that as recently shown by Herrmann and coworkers (personal communication) by an analytical ultracentrifugation approach K18 normally exists as monomer while $\mathrm{K} 8$ is a mixture of various polymers. These data underline the significant contribution of IFs to protein aggregation disorders and diseases, which still have to be elucidated in further studies.

MDB generation clearly requires additional stimuli like oxidative stress leading to overexpression of the stress protein p $62,{ }^{39}$ and eventually transglutaminase-induced crosslinking, as shown in vitro with cells transfected with major MDB components and in other studies. ${ }^{25,40,41}$ In this context, p62 may have a dualistic role by aggregating abnormal ubiquitinated proteins but also by shuttling them to the proteasomal and/or autophagosomal machineries. ${ }^{39,42}$ The role of impaired K-related proteolysis in MDB formation is supported by our immunoblotting and immunofluorescence data showing persistence of K8 in hepatocytes of chronically intoxicated $\mathrm{krt}_{1} 8^{-/-}$mouse livers (Supplementary Figure 2).

The decreased apoptosis rate in $\mathrm{krt}^{-1-}$ and $\mathrm{krt}^{-18^{-1-}}$ mice, particularly in the state of chronic intoxication (see also Zatloukal et $a^{23}$ ), was unexpected as Ks protect hepatocytes against Fas-induced apoptosis. ${ }^{43}$ Since p62 has a complex role in apoptosis induction and cell survival pronounced accumulation and aggregation of this protein may be critical in DDC intoxication. In any case, apoptosis does not seem to have a major role in hepatocyte disposal in the DDC model in contrast to human steatohepatitis, in which apoptosis significantly contributes to hepatocyte loss. ${ }^{44}$

Since $k r t$ mutations predispose to end-stage liver disease we examined the impact of Ks on DDC-induced biliary fibrosis and sclerosing cholangitis. ${ }^{10,11,44}$ Based on our results, we conclude that the $\mathrm{K}$ status has no influence on the complex biliary pathology associated with DDC intoxication.

OPN has recently been described as being induced by hedgehog ( $\mathrm{Hh}$ ) signaling, and to promote fibrogenesis in NASH-related cirrhosis. ${ }^{45}$ As in 1-week DDC-treated mice $\mathrm{OPN}^{+}$granules appear in zone 1 hepatocytes further studies on the relationship between keratin integrity and $\mathrm{Hh}$ signaling in acute liver toxicity will be needed. However, as in chronically DDC-intoxicated animals $\mathrm{OPN}^{+}$hepatocytes decrease in number or even disappear irrespective of the $\mathrm{K}$ status chronically induced $\mathrm{K}$ alterations do not seem to be linked to OPN.

Ductular reaction is a prominent feature of prolonged DDC intoxication and even more pronounced in intoxicated K-deficient mice. Ductular proliferation may represent a sign of parenchymal regeneration following injury, and may also be triggered by incomplete mechanical biliary obstruction. ${ }^{46}$ 
In the DDC model, both possibilities exist resulting from a combination of parenchymal damage and mechanical cholestasis. ${ }^{47}$ Further studies are needed to clarify the question how relevant our findings are in the context of human steatohepatitis.

Based on our data and results from other groups, multiple genetic backgrounds should be investigated to understand keratin biology and its disease relevance as obviously for different functional aspects various genetic backgrounds lead to different degrees of susceptibility. Therefore, the direct comparison with human liver specimens can be clearly seen as gold standard. However, as model systems mice are highly representative as demonstrated in many publications on IFs.

In summary, $\mathrm{krt}^{-1-}$ and $\mathrm{krt}^{-18^{-1-}}$ mice on the same genetic background show similar sensitivity to DDC intoxication and almost resemble wt animals regarding survival, degree of porphyria, liver-to-body weight ratios, serum bilirubin and liver enzyme levels. This stands in contrast to previous work where $\mathrm{krt}^{-1-}$ and $\mathrm{krt1} 18^{-1-}$ mice on different genetic backgrounds were analyzed. However, our key finding was that upon DDC feeding $\mathrm{krt}_{1} 8^{-/-}$mice developed MDBs while $\mathrm{krt}^{-1-}$ mice did not, suggesting that there are key differences in keratin intrinsic properties. We here demonstrate that the structural properties of K8 and K18 are genetic modifiers, which are independent of genetic background effects while toxicity effects depend on the genetic background.

Supplementary Information accompanies the paper on the Laboratory Investigation website (http://www.laboratoryinvestigation.org)

\section{ACKNOWLEDGEMENTS}

We thank Dr Helene Baribault (The Burnham Institute, La Jolla, CA) for providing the $\mathrm{krt}^{-1-}$ mice. This study was supported by the grants of the Austrian Science Fund S7401-MOB, and the Austrian Genome Program to KZ and MT by German Research Association Grants (SFB 284/07 and MA 1316/9-3) to TMM. JH was in part supported by the 'Lore Saldow grant' and the 'Kurt und Senta Herrmann foundation'.

\section{DISCLOSURE/CONFLICT OF INTEREST}

The authors declare no conflict of interest.

\section{Author contributions}

$\mathrm{JH}$ and PF contributed to concept, experimentation, data analysis and manuscript writing; CS contributed to experimentation, data analysis and manuscript writing; AT contributed to experimentation, immunofluorescence of tissues and data analysis; TMM and MT contributed to concept, data analysis and manuscript writing; TK, MH and OT contributed to experimentation and data analysis; $\mathrm{HM}$ performed statistical analysis; $\mathrm{KZ}$ and HD contributed to concept, funding, experimentation, data analysis and manuscript writing.

1. Herrmann $H$, Bar $H$, Kreplak L, et al. Intermediate filaments: from cell architecture to nanomechanics. Nat Rev Mol Cell Biol 2007;8:562-573.

2. Magin TM, Vijayaraj P, Leube RE. Structural and regulatory functions of keratins. Exp Cell Res 2007;313:2021-2032.

3. Hesse $M$, Grund $C$, Herrmann $H$, et al. A mutation of keratin 18 within the coil $1 \mathrm{~A}$ consensus motif causes widespread keratin aggregation but cell type-restricted lethality in mice. Exp Cell Res 2007;313: 3127-3140.

4. Coulombe PA, Wong P. Cytoplasmic intermediate filaments revealed as dynamic and multipurpose scaffolds. Nat Cell Biol 2004;6:699-706.
5. Baribault $\mathrm{H}$, Price J, Miyai K, et al. Mid-gestational lethality in mice lacking keratin 8. Genes Dev 1993;7:1191-1202.

6. Vijayaraj $\mathrm{P}$, Kroger $\mathrm{C}$, Reuter $\mathrm{U}$, et al. Keratins regulate protein biosynthesis through localization of GLUT1 and -3 upstream of AMP kinase and Raptor. J Cell Biol 2009;187:175-184.

7. Tamai Y, Ishikawa T, Bosl MR, et al. Cytokeratins 8 and 19 in the mouse placental development. J Cell Biol 2000;151:563-572.

8. Hillebrandt S, Goos C, Matern S, et al. Genome-wide analysis of hepatic fibrosis in inbred mice identifies the susceptibility locus Hfib1 on chromosome 15. Gastroenterology 2002;123:2041-2051.

9. Omary $\mathrm{MB}, \mathrm{Ku} \mathrm{NO}$, Toivola DM. Keratins: guardians of the liver. Hepatology 2002;35:251-257.

10. Ku NO, Lim JK, Krams SM, et al. Keratins as susceptibility genes for endstage liver disease. Gastroenterology 2005;129:885-893.

11. Ku NO, Strnad P, Zhong BH, et al. Keratins let liver live: mutations predispose to liver disease and crosslinking generates Mallory-Denk bodies. Hepatology 2007;46:1639-1649.

12. Strnad P, Stumptner C, Zatloukal K, et al. Intermediate filament cytoskeleton of the liver in health and disease. Histochem Cell Biol 2008;129:735-749.

13. Stumptner $C$, Omary MB, Fickert $P$, et al. Hepatocyte cytokeratins are hyperphosphorylated at multiple sites in human alcoholic hepatitis and in a Mallory body mouse model. Am J Pathol 2000;156:77-90.

14. Toivola DM, Ku NO, Resurreccion EZ, et al. Keratin 8 and 18 hyperphosphorylation is a marker of progression of human liver disease. Hepatology 2004;40:459-466.

15. Ku NO, Omary MB. A disease- and phosphorylation-related nonmechanical function for keratin 8. J Cell Biol 2006;174:115-125.

16. Omary MB, Ku NO, Tao GZ, et al. 'Heads and tails' of intermediate filament phosphorylation: multiple sites and functional insights. Trends Biochem Sci 2006;31:383-394.

17. Ku NO, Soetikno RM, Omary MB. Keratin mutation in transgenic mice predisposes to Fas but not TNF-induced apoptosis and massive liver injury. Hepatology 2003;37:1006-1014.

18. Marceau N, Schutte B, Gilbert S, et al. Dual roles of intermediate filaments in apoptosis. Exp Cell Res 2007;313:2265-2281.

19. Denk H, Stumptner C, Zatloukal K. Mallory bodies revisited. J Hepatol 2000;32:689-702.

20. Zatloukal K, French SW, Stumptner C, et al. From Mallory to MalloryDenk bodies: what, how and why? Exp Cell Res 2007;313:2033-2049.

21. Hanada S, Strnad P, Brunt EM, et al. The genetic background modulates susceptibility to mouse liver Mallory-Denk body formation and liver injury. Hepatology 2008;48:943-952.

22. Omary MB. 'IF-pathies': a broad spectrum of intermediate filamentassociated diseases. J Clin Invest 2009;119:1756-1762.

23. Zatloukal K, Stumptner C, Lehner M, et al. Cytokeratin 8 protects from hepatotoxicity, and its ratio to cytokeratin 18 determines the ability of hepatocytes to form Mallory bodies. Am J Pathol 2000;156: 1263-1274.

24. Strnad P, Zatloukal K, Stumptner C, et al. Mallory-Denk-bodies: lessons from keratin-containing hepatic inclusion bodies. Biochim Biophys Acta 2008;1782:764-774.

25. Stumptner C, Fuchsbichler A, Zatloukal K, et al. In vitro production of Mallory bodies and intracellular hyaline bodies: the central role of sequestosome 1/p62. Hepatology 2007;46:851-860.

26. Stumptner $\mathrm{C}$, Fuchsbichler $\mathrm{A}$, Heid $\mathrm{H}$, et al. Mallory body-a diseaseassociated type of sequestosome. Hepatology 2002;35:1053-1062.

27. Fickert $P$, Trauner $M$, Fuchsbichler $A$, et al. Bile acid-induced Mallory body formation in drug-primed mouse liver. Am J Pathol 2002;161: 2019-2026.

28. Brunt EM, Janney CG, Di Bisceglie AM, et al. Nonalcoholic steatohepatitis: a proposal for grading and staging the histological lesions. Am J Gastroenterol 1999;94:2467-2474.

29. Toivola DM, Nieminen Ml, Hesse M, et al. Disturbances in hepatic cellcycle regulation in mice with assembly-deficient keratins 8/18. Hepatology 2001;34:1174-1183.

30. Rangaswami H, Bulbule A, Kundu GC. Osteopontin: role in cell signaling and cancer progression. Trends Cell Biol 2006;16:79-87.

31. Lorena D, Darby IA, Gadeau AP, et al. Osteopontin expression in normal and fibrotic liver. Altered liver healing in osteopontin-deficient mice. J Hepatol 2006;44:383-390.

32. Rangaswami H, Bulbule A, Kundu GC. Nuclear factor inducing kinase: a key regulator in osteopontin- induced MAPK/lkappaB kinase 
dependent NF-kappaB-mediated promatrix metalloproteinase-9 activation. Glycoconj J 2006;23:221-232.

33. Lee $\mathrm{SH}$, Seo GS, Park YN, et al. Effects and regulation of osteopontin in rat hepatic stellate cells. Biochem Pharmacol 2004;68:2367-2378.

34. Pallari HM, Eriksson JE. Intermediate filaments as signaling platforms. Sci STKE 2006;2006:pe53.

35. Magin $T M$, Schroder $R$, Leitgeb $S$, et al. Lessons from keratin 18 knockout mice: formation of novel keratin filaments, secondary loss of keratin 7 and accumulation of liver-specific keratin 8-positive aggregates. J Cell Biol 1998;140:1441-1451.

36. Nakamichi I, Toivola DM, Strnad P, et al. Keratin 8 overexpression promotes mouse Mallory body formation. J Cell Biol 2005;171:931-937.

37. Harada $M$, Strnad $P$, Resurreccion EZ, et al. Keratin 18 overexpression but not phosphorylation or filament organization blocks mouse Mallory body formation. Hepatology 2007;45:88-96.

38. Mahajan V, Klingstedt T, Simon R, et al. Cross beta-sheet conformation of keratin 8 is a specific feature of Mallory-Denk bodies compared to other hepatocyte inclusions. Gastroenterology 2011;141:1080-1090. e1-7.

39. Moscat J, Diaz-Meco MT. p62 at the crossroads of autophagy, apoptosis, and cancer. Cell 2009;137:1001-1004.
40. Nan L, Wu Y, Bardag-Gorce F, et al. p62 is involved in the mechanism of Mallory body formation. Exp Mol Pathol 2004;77:168-175.

41. Strnad $P$, Harada $M$, Siegel $M$, et al. Transglutaminase 2 regulates Mallory body inclusion formation and injury-associated liver enlargement. Gastroenterology 2007;132:1515-1526.

42. Moscat J, Diaz-Meco MT. To aggregate or not to aggregate? A new role for p62. EMBO Rep 2009;10:804.

43. Ku NO, Gish R, Wright TL, et al. Keratin 8 mutations in patients with cryptogenic liver disease. N Engl J Med 2001;344:1580-1587.

44. Fickert $\mathrm{P}$, Stoger $\mathrm{U}$, Fuchsbichler $\mathrm{A}$, et al. A new xenobiotic-induced mouse model of sclerosing cholangitis and biliary fibrosis. Am J Pathol 2007:171:525-536.

45. Syn WK, Choi SS, Liaskou E, et al. Osteopontin is induced by hedgehog pathway activation and promotes fibrosis progression in nonalcoholic steatohepatitis. Hepatology 2011;53:106-115.

46. Desmet VJ, van Eyken $\mathrm{P}$, Roskams T. Histopathology of vanishing bile duct diseases. Adv Clin Path 1998;2:87-99.

47. Zollner $G$, Wagner M, Fickert $P$, et al. Expression of bile acid synthesis and detoxification enzymes and the alternative bile acid efflux pump MRP4 in patients with primary biliary cirrhosis. Liver Int 2007;27: 920-929. 